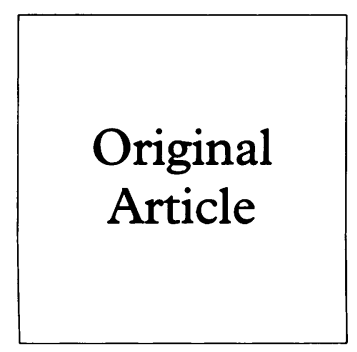

\title{
HIV partner notification policy and practice within GUM clinics in England: where are we now?
}

\author{
K A Fenton, A Copas, A M Johnson, R French, A Petruckevitch, $M$ W Adler
}

Objectives: To evaluate the extent to which larger genitourinary medicine (GUM) clinics in England have established local clinic policies for HIV Partner Notification (PN) and to describe the process of HIV PN within this setting.

Design: A cross-sectional survey of HIV PN policies and practices within GUM clinics.

Subjects and setting: Senior consultants in 59 GUM clinics in England.

Main outcome measures: The presence of clinic policies for HIV PN, indicators of HIV PN activity (that is, its initiation, documentation, performance and evaluation) and factors hindering the acceptance of HIV PN into clinical practice.

Results: Only $18 \%(10 / 57)$ of respondents stated that their clinics had developed their own local policies for HIV PN. Fifteen percent (9/58) of clinics had audited HIV PN activity, $15 \%$ had provided specific HIV PN training for doctors and $47 \%(27 / 58)$ for health advisers. Within GUM clinics, health advisers play a key role in the HIV PN process, being responsible for initiating the discussion of partners, patient follow-up and documenting HIV PN activity in patients' notes. Notifying partners was primarily seen as the responsibility of the newly diagnosed HIV positive patient. Although $77 \%(43 / 56)$ of responding consultants believed that HIV PN had become an accepted part of their clinics' practice, the perceived unacceptability of HIV PN to patients and health care workers were seen as important limiting factors.

Conclusion: In many GUM clinics, local policies on HIV PN have yet to be established and appropriate training for the health personnel provided. Nevertheless, there appears to be widespread acceptance of HIV PN in clinical practice with an acknowledgement of its limiting factors. Further research into the acceptability of HIV PN to health care workers and patients in this setting should be undertaken.

(Genitourin Med 1997;73:49-53)

Keywords: partner notification; policy; clinical practice

\section{Introduction}

Partner notification (or contact tracing) has been advocated as a strategy for the control of sexually transmitted diseases (STDs) ${ }^{1}$ and, more recently, Human Immunodeficiency Virus (HIV) infection. ${ }^{23}$ In December 1992, the Department of Health ( $\mathrm{DoH})$, England, issued its first national guidance ${ }^{4}$ concerning partner notification (PN) for HIV infection. The guidance aimed to assist health care professionals, Health Authorities and Trusts in developing local policies for the notification of partners or contacts of HIV infected persons, and was circulated predominantly to Regional and District level managers. The guidance stressed that PN should not be an isolated activity but "part of comprehensive, coordinated HIV and STD prevention, care and support programmes".

The degree to which the DoH guidance has been taken up by the GUM specialty and formulated into local clinic policies is unknown. This may be influenced by attitudes among health care workers towards HIV $\mathbf{P N}^{5}$ or their perception of roles and responsibilities on PN. ${ }^{6}$ The HIV Partner Notification Project, ${ }^{7}$ a Department of Health funded evaluation of the implementation, outcomes and resource requirements of an active HIV PN strategy among 19 GUM clinics in England provided some insight into partner notification practices. The project demonstrated that although there was documented evidence in case notes of partners being discussed with most $(75 \%)$ newly diagnosed HIV patients, there was no documented evidence of the outcomes of PN in over half $(58 \%)$ of patients seen during the one year study period. The project also revealed that inconsistent clinic attendance and health care workers' assessment of patients' ability to discuss or undertake PN, often impacted negatively on the HIV PN process.

The aim of this study was to determine the extent to which clinic policies on HIV PN exist and to describe current PN practices among larger GUM clinics in England. In this paper, we present the findings related to these objectives and explore factors which GUM consultants felt might influence HIV PN within clinics.

\section{Methods}

This cross-sectional study of a selected group of GUM clinics in England was undertaken in June 1995. The Department of Health's National List of GUM clinics for $1994^{8}$ provided a comprehensive listing of all national clinics, with staffing and opening times. Clinics were eligible to participate in the study if they were open daily, were not satellite clinics of larger GUM centres and employed at least one full time health adviser. Seventy-two clin- 
Table 1 Distribution of demographic characteristics among responding clinics according to participation in the HIV PN Project and clinic location

\begin{tabular}{|c|c|c|c|c|}
\hline Demographic characteristics & $\begin{array}{l}\text { London clinics } \\
(n=14) \dagger\end{array}$ & $\begin{array}{l}\text { Clinics outside } \\
\text { London } \\
(n=45) \dagger\end{array}$ & $\begin{array}{l}\text { Participated in } \\
H I V P N \text { project } \\
(n=14)\end{array}$ & $\begin{array}{l}\text { Clinics not in } \\
\text { HIV PN project } \\
(n=45) \dagger\end{array}$ \\
\hline $\begin{array}{l}\text { Number of consultants } \\
\text { (whole time equivalent, WTE)* }\end{array}$ & $2 \cdot 0(0.7-6 \cdot 0)$ & $1.5(0.6-4.0)$ & $2 \cdot 4(1 \cdot 7-6 \cdot 0)$ & $1 \cdot 0(6-6 \cdot 0) \ddagger$ \\
\hline Number of training grade medical & $1.4(0.0-13.0)$ & $0.2(0.0-7.0) t$ & $2(0-13)$ & $0 \cdot 1(0-7)$ \\
\hline $\begin{array}{l}\text { Number of clinical assistants (WTE) } \\
\text { Number of health advisers (WTE) }\end{array}$ & $\begin{array}{l}1 \cdot 4(0 \cdot 0-13 \cdot 0) \\
1 \cdot 3(0 \cdot 0-5 \cdot 0) \\
3 \cdot 0(1 \cdot 0-8 \cdot 0)\end{array}$ & $\begin{array}{l}0.2(0 \cdot 0-1 \cdot 0) \mp \\
0.9(0 \cdot 0-10 \cdot 0) \\
2 \cdot 0(0 \cdot 0-5 \cdot 0) \ddagger\end{array}$ & $\begin{array}{l}2(0-13) \\
1(0-5) \\
4(1-8)\end{array}$ & $\begin{array}{l}0 \cdot 1(0-10) \\
2(0-8) \ddagger\end{array}$ \\
\hline $\begin{array}{l}\text { Number of clinic attendances (STD and } \\
\text { HIV) for } 1994^{\star}\end{array}$ & $\begin{array}{l}15082 \\
(8469-60000)\end{array}$ & $\begin{array}{c}10127 \ddagger \\
1285-28000)\end{array}$ & $\begin{array}{l}21469 \\
8469-56000)\end{array}$ & $\begin{array}{l}9885 \ddagger \\
(1285-60000)\end{array}$ \\
\hline $\begin{array}{l}\text { Number of newly diagnosed HIV positive } \\
\text { patients seen in } 1994^{\star}\end{array}$ & $23(2-180)$ & $5(0-58) \ddagger$ & $16 \cdot 5(2-180)$ & $6(0-50) \ddagger$ \\
\hline
\end{tabular}

^Figures shown are median (range).

†Missing data for some clinics.

$\neq \mathrm{p}<0.05$.

ics, including the 19 clinics that had previously participated in the HIV PN Project, ${ }^{7}$ fulfilled these criteria. In general, selected clinics were located in larger towns or cities and were therefore presumed to have a greater likelihood of managing HIV patients.

The senior clinic consultant (or the lead clinician for HIV/AIDS patient care, if known) in the 72 selected clinics was sent a three part questionnaire for self-completion. The first part contained questions on the number of medical staff and health advisers employed in the clinic, clinic attendance and the number of newly diagnosed HIV positives seen in the preceding year. The second part sought information on various aspects of clinic policy and practice related to HIV PN including the presence of specific clinic policies on PN, PN management of newly diagnosed HIV positive patients, PN for other STDs, audit or teaching activities surrounding PN. In the final part, consultants were asked to share their own views on the incorporation of HIV partner notification into clinical practice. Questionnaires were sent by mail at the end of May 1995, with reminders sent to non-responders after three weeks. Non-responders were sent another questionnaire 5 weeks after the initial mail-out, reminded by telephone and offered completion by telephone interview.

The quantitative data from the first two parts of the questionnaire were analysed using SPSS. Proportions were compared with the chi square test and the Mann Whitney test was used to evaluate differences between subgroups with respect to continuous variables (such as WTE staff). Multiple logistic regression was used to simultaneously evaluate the influence of various demographic factors (for example, clinic location, size, HIV caseload) on the development of HIV PN clinic activities and policies. Qualitative data from the third part of the questionnaire were categorised and analysed to determine major themes.

\section{Results}

Completed questionnaires were returned from consultants in 59 of the 72 clinics surveyed (82\% response rate). Seventy-four percent (14/19) of HIV PN Project clinics and 85\% $(45 / 53)$ of non-Project clinics responded. Seventy percent $(14 / 20)$ of clinics in London and $87 \%(45 / 52)$ of clinics outside London responded. The demographic characteristics of participating clinics are shown in table 1. Of note, clinics which participated in the HIV PN $\vec{\circ}$ Project and clinics located within London $\overrightarrow{\vec{\omega}}$ had significantly higher median numbers of clinic attendances in the previous year, and $\stackrel{\infty}{=}$ saw more newly diagnosed HIV positive $\omega$ patients.

Written policies for HIV PN

were asked if their clinics had developed their own written policies for HIV PN. Only $10(18 \%)$ of the 57 responding clinics had developed, and were using, their own written policies and $35(61 \%)$ were using no $\overrightarrow{0}$ local policy or guide for HIV PN. Twelve clinics $(21 \%)$, predominantly participants in the HIV PN Project, had not developed their own policies but were using the HIV PN Project manual $^{9}$ as a guide. Clinics located in London (33\% vs. $12 \%$ ) and clinics which participated $\stackrel{\varnothing}{\triangle}$ in the Project ( $29 \%$ vs. $14 \%$ ) were more likely $\overrightarrow{\overrightarrow{0}}$ to have developed their own HIV PN clinic policies, but these differences were not statistically significant. The development of local written policies on HIV PN was not significantly associated with the median number of $\frac{5}{3}$ clinic attendances per year and the median number of new HIV positives seen in the preceding year.

The process of HIV PN within GUM clinics We asked which health professionals were primarily responsible for giving patients their first ? positive HIV test result. Forty-nine percent of ${ }^{N}$ respondents stated that only doctors in their $\omega$ clinics gave these results, in $29 \%$ only health advisers, and in $20 \%$, either a doctor or health adviser gave these results. Clinic location influenced this process, with clinics inside London more likely to use only health advisers ( $53 \%$ vs. $20 \%, p=0.036$ ), and less likely to use only doctors to give a positive result $(20 \% \stackrel{\mathbb{Q}}{\Omega}$ vs. $59 \%, p=0.02)$ compared with clinics outside London.

The distribution of responsibilities for various aspects of HIV PN are shown in table 2 . Health advisers were seen as taking the primary role in most stages of the HIV PN process, from initiating the discussion on HIV PN, documenting its outcomes and being responsible for ensuring that contacts were notified. Newly diagnosed patients were seen as responsible for actually undertaking 
Table 2 Distribution of responsibilities in the process of HIV partner notification within GUM clinics

\begin{tabular}{|c|c|c|c|c|c|}
\hline HIV PN responsibility & Doctors & Health Advisers & The patient & $\begin{array}{l}\text { Other health } \\
\text { professional }\end{array}$ & $\begin{array}{l}\text { No one in } \\
\text { particular }\end{array}$ \\
\hline 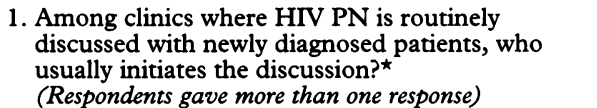 & $27 / 54(50 \%)$ & $42 / 54(78 \%)$ & $3 / 56(6 \%)$ & $3 / 56(6 \%)$ & $0 \%$ \\
\hline $\begin{array}{l}\text { 2. Who is responsible for ensuring that contacts of } \\
\text { newly diagnosed HIV patients have been } \\
\text { notified?*} \\
\text { (Respondents gave more than one response) }\end{array}$ & $14 / 59(24 \%)$ & $43 / 59(73 \%)$ & $19 / 59(42 \%)$ & $0 \%$ & $0 \%$ \\
\hline $\begin{array}{l}\text { 3. Who is responsible for notifying the contacts of } \\
\text { newly diagnosed HIV patients? } \\
\text { (Respondents gave more than one response) }\end{array}$ & $5 / 58(9 \%)$ & $29 / 58(50 \%)$ & $49 / 58(85 \%)$ & $0 \%$ & $0 \%$ \\
\hline $\begin{array}{l}\text { 4. Who is responsible for documenting the outcome } \\
\text { of HIV PN in patients' case notes? }{ }^{\star}\end{array}$ & $10 / 56(18 \%)$ & $39 / 56(69 \%)$ & $0 \%$ & $0 \%$ & $7 / 56(13 \%)$ \\
\hline
\end{tabular}

^No statistically significant association with clinic location, participation in the HIV PN Project, clinic size or number of HIV

patients seen.
$+100 \%$ of respondents from London stated that the patient was primarily responsible for notification, compared with $79 \%$ of clinics outside of London.

notification (patient referral). This belief was particularly held by respondents from London who unanimously saw patients as primarily responsible for the notification of partners (as compared with $79 \%$ of respondents from outside London, $\mathrm{p}<0.05)$. Overall $50 \%$ of respondents viewed health advisers as having some responsibility for undertaking HIV PN (provider referral); this was somewhat more likely among outside London respondents ( $55 \%$ vs. $33 \%$ ).

The acceptance of HIV PN into clinical practice Consultants were asked whether they felt HIV PN had become an accepted part of their clinic's practice and if there were any factors which hindered this process. Although $77 \%$ responded that HIV PN had become an accepted part of their clinic's practice, all respondents thought that there were factors which hindered this process (see fig). The most common limiting factor (mentioned by $73 \%$ of respondents) was health care workers' concerns about the unacceptability of HIV PN to patients. This belief was unrelated to clinic size, location, participation in the HIV PN Project or the number of HIV positive patients seen in that clinic. Patients transferring between treatment centres or defaulting from

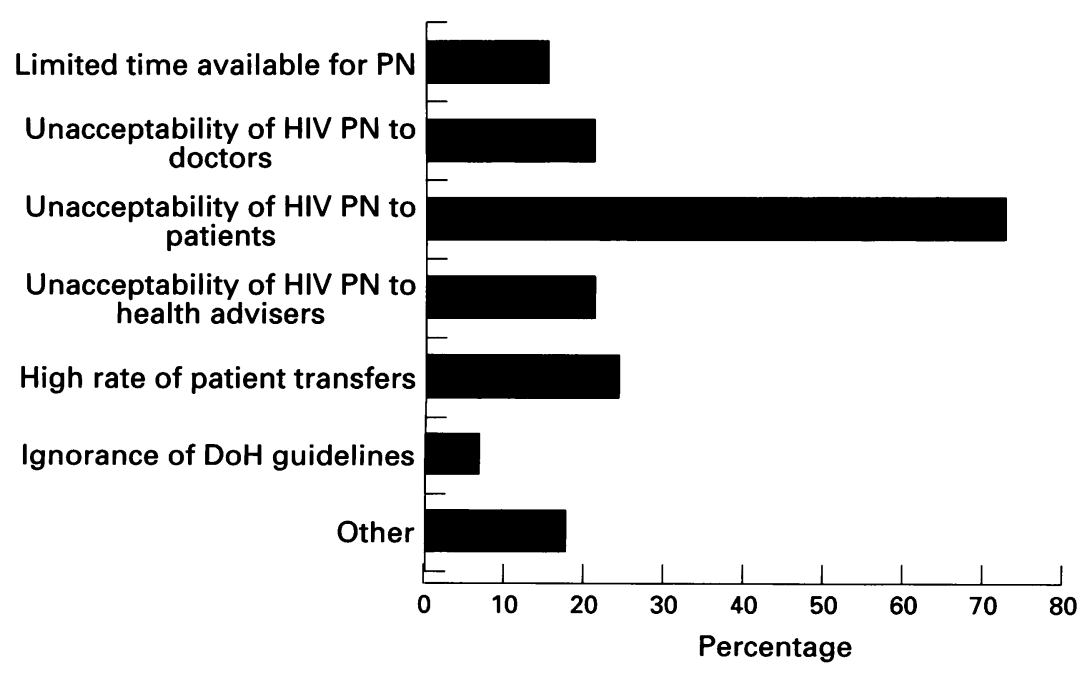

Distribution of GUM consultants opinion of factors which have hindered HIV PN becoming a fully accepted part of their clinic's practice? $(n=59)$. clinic prevented continuity of care and was also seen to impact negatively on initiating and completing HIV PN within clinics. Only 16\% of respondents believed that not enough time was available for HIV PN.

\section{Clinic activities involving HIV PN}

The degree to which the subject of HIV PN had become part of clinic practice was assessed by asking whether clinics had held any audits, training (for doctors and health advisers), or clinic meetings/teachings specifically dedicated to HIV PN. Table 3 shows the distribution of these activities among responding clinics. Only training for health advisers on HIV PN and holding clinic meetings on HIV PN were significantly associated with having participated in the HIV PN Project. Multivariate analysis indicated that performing clinical audits, holding clinic meetings and providing training for doctors on HIV PN were all unrelated to clinic size, participation in the HIV PN Project or the number of newly diagnosed HIV positives seen in the preceding year.

\section{Consultant's comments on partner notification}

Thirty-four consultants $(58 \%)$ responded to the third part of the questionnaire, providing additional comments on HIV PN. Most responses were from clinicians outside London not associated with the HIV PN Project. In general, respondents felt that PN was an important activity which should be routinely discussed with patients. Doubts were expressed concerning the practicalities of HIV PN within GUM clinics; for example, when should HIV PN be initiated, by whom, and in which patients is it most appropriate. It was felt that each patient and the individual circumstances should be taken into account, with PN being offered at an appropriate time in the consultation. Attitudes toward provider referral were more hesitant, and seen as being the second best option. A few clinicians felt that HIV PN was entirely the patient's responsibility.

Another key issue was client confidentiality, especially among the disadvantaged, refugees or certain ethnic minority groups. There was a real concern about $\mathrm{PN}$, if handled inappropri- 
Table 3 Distribution of clinic activities dedicated to HIV partner notification

\begin{tabular}{lccc}
\hline HIV PN related clinic activity & $\begin{array}{l}\text { HIV PN } \\
\text { project clinics }\end{array}$ & $\begin{array}{l}\text { Clinics not in } \\
\text { pIV PN }\end{array}$ & project \\
\hline $\begin{array}{l}\text { Clinical audit(s) held on partner } \\
\text { Notification for HIV infection }\end{array}$ & $4 / 14(29 \%)$ & $5 / 44(11 \%)$ & $9 / 58(15 \%)$ \\
$\begin{array}{l}\text { Training for doctors on partner notification } \\
\begin{array}{l}\text { Training for health advisers on partner } \\
\text { notification }\end{array}\end{array}$ & $2 / 14(14 \%)$ & $8 / 44(18 \%)$ & $10 / 58(17 \%)$ \\
$\begin{array}{l}\text { Clinic meetings or dedicated teaching } \\
\quad \text { sessions on HIV PN }\end{array}$ & $12 / 14(86 \%)$ & $15 / 44(34 \%)^{\star}$ & $27 / 58(47 \%)$ \\
$\begin{array}{l}\text { Has HIV PN become accepted in clinic } \\
\text { practice? }\end{array}$ & $12 / 14(86 \%)$ & $22 / 24(52 \%)^{\star}$ & $36 / 56(61 \%)$ \\
\hline${ }^{\star} \mathrm{p}<0.05$. & $12 / 14(86 \%)$ & $31 / 42(74 \%)$ & $43 / 56(77 \%)$ \\
\hline
\end{tabular}

ately, leading to identification and ostracisation of individuals from their local communities. In general, consultants felt that there remained many issues on HIV PN which needed to be discussed between the various professional groups and within the GUM specialty. Calls for audit of HIV PN, further research (especially surrounding the acceptability to patients and health care workers) and clearer guidelines were made.

\section{Discussion}

This survey evaluated the extent to which HIV $\mathrm{PN}$, as outlined in the Department of Health (DoH) guidance, has been incorporated into the policies and practices of the larger GUM clinics in England. It was undertaken two and a half years after the DoH guidance on HIV PN was issued and has demonstrated a relatively poor uptake of its two principal recommendations: The development of local HIV PN clinic policies, and the provision of appropriate training for health care workers involved in PN. At a managerial level, dissemination of the guidance to senior and middle level managers and not directly to local clinic consultants and senior health advisers may have contributed to this poor uptake. At the clinic level, doubts concerning the acceptability of HIV PN to patients and staff as well as deficient monitoring of clinic policy development may have also contributed. Any further guidance in this area should therefore take these factors into consideration.

Although the majority of responding consultants felt that HIV PN had become an accepted part of clinic practice, the results do suggest that the development of local clinic policies has, to date, been fairly random, unrelated to clinic workload, HIV patient throughput or clinic location, and little influenced by participation in the HIV PN Project. Participation in the HIV PN Project was associated with increased use of local HIV PN clinic policies, an increased profile of PN within participating clinics (through clinic meetings) and training for health advisers (at a 3 day residential training course).

The development of local clinic policies on HIV PN which are appropriate and acceptable to newly diagnosed patients and clinic staff represents one strategy by which GUM clinics can facilitate the incorporation of HIV PN into clinic practice. Clinic policies should aim at clarifying responsibilities for HIV PN recognising the complementary roles of doctors and health advisers. Clinical audit has been advocated as an essential tool in evaluating policies and improving the quality of services. ${ }^{10}$ Although many GUM clinics regularly audit STD contact tracing activity, very few clinics reported doing this for HIV infection. This may be a reflection of HIV PN not being $\stackrel{\mathbb{D}}{\triangle}$ incorporated into the audit cycle or absento clinic policies which inhibit structured evaluation of HIV PN process and outcomes. With the establishment of policy-guided standards, $\stackrel{\mathbb{Q}}{\circ}$ regular evaluation of the process through clinical audit will be facilitated.

The DoH guidelines specified that training? for all staff involved in HIV PN was necessary음 to equip health care workers with the special ${ }_{\bar{\sigma}}$ skills needed to perform their tasks effectively. In this survey, the lack of training provided for ${ }^{\text {cs }}$ health advisers and doctors who are likely to $\vec{\circ}$ be undertaking HIV PN, points to an impor- $\overrightarrow{\vec{\omega}}$ tant area of unmet need. Training on HIV PNO should include, at minimum, techniques for? efficient and acceptable patient and provider $\omega$ referral, methods of dealing with confidentiality. issues and potential complications of PN. Training should be ongoing to ensure that new을 staff are afforded the appropriate skills to carry out PN effectively and confidently.

Responding consultants perceived the unacceptability of HIV PN to patients as the most important factor limiting HIV PN in their clinic. Patients' concerns with respect to confi-e dentiality, fear of domestic violence, identification and marginalisation by their communities? were cited as possible reasons why PN may be unacceptable among clients with the endo result of "driving patients away from the $\stackrel{\complement}{\stackrel{\Phi}{\varrho}}$ health service". The few studies which have $\vec{\nexists}$ examined the acceptability of HIV PN among 3 index patients and their contacts ${ }^{11}$ suggest high acceptability among patients and contacts: when $P N$ is performed in a professional and? highly skilled manner by trained personnel. The concerns expressed about the acceptabil ity of PN to health care workers verifies earliero findings by Keenlyside et al. ${ }^{7}$ Further, more focused work into the acceptability of HIV PN? among newly diagnosed patients is needed to determine whether these concerns are justified and to identify strategies for overcoming them. Another strategy for improving the uptake of HIV PN within the GUM setting includes working with special groups for whom PNO may be difficult, threatening or overlooked, such as intravenous drug users, certain ethnice minority groups and young gay men, to develop appropriate $\mathrm{PN}$ programmes.

In conclusion, although there appears to be widespread conceptual acceptance of the HIV $\mathrm{PN}$ as a strategy, in reality there are manyo practical issues within GUM clinics which remain unaddressed. For this strategy to beo taken onboard fully further commitment to policy development, exploring attitudes? towards HIV PN and health care worker training will be needed.

We thank Dr Johan Giesecke, Ms Sue Trotter and Mr John Howson for the advice given as part of the HIV PN Project Steering Group, and the Department of Sexually Transmitted 
Diseases, Division of Pathology and Infectious Diseases, UCI Medical School and Camden and Islington Community Health Services NHS Trust for the support provided.

Funding: The Department of Health, England.

Conflict of Interest: None.

1 Cates W, Mehus A. Strategies for development of sexually transmitted disease control programmes. In: Holmes $\mathrm{KK}$ Mardh P-A Parling PF, Wiesner PJ, eds. Sexually Transmitted Diseases. New York: McGraw-Hill, 1990: 1023-30.

2 Potterat JJ, Spencer NE, Woodhouse DE, Muth JB. Partner notification in the control of human immunodeficiency virus infection. Am $\mathcal{F}$ Public Health 1989;79:874-6.

3 Cates W, Toomey K, Havlak RG, Bowen GS, Hinman AR Partner notification and confidentiality of the index patient: Its role in preventing HIV. Sex Transm Dis 1990; 17:113-4.

4 Guidance for Partner Notification for HIV Infection Department of Health. December 1992. PL/CO (92).

5 Keenlyside RA, Hawkins AS, Johnson AM, Adler MW. Attitudes towards tracing and notifying contacts of peo- ple with HIV infection. BMF 1992;305:165-8.

6 Allen I, Hogg D. Work roles and responsibilities in genitournary medicine clinics. Policy Studies Institute, 1993.

7 Adler M, Fenton K, French R, Giesecke J, Howson J, Johnson AM, et al. Report of the HIV Partner Notification Project. A Department of Health funded evaluation of the resource requirements and outcomes of partner notification for HIV infection as outlined in the December 1992 DoH guidelines. London, September December 1992 DoH guidelines. London, September 1995.

8 List of Genito-Urinary Medicine Clinics in the United Kingdom and the Republic of Ireland. Department of Health, London 1994.

9 HIV PN Project Steering Group. The Partner Notification Project Protocol and Manual. Version 2. London March 1994.

10 Mercey D. Clinical audit in genitourinary medicine "Why, Who, What, How and When?" Genitourin Med 1994;68: 205-6.

11 Jones JL, Wykoff RF, Hollis SL, Longshore ST, Gamble W, Gumm RA, et al. Partner acceptance of Health Department notification of HIV exposure, South Carolina. $\mathscr{F} A M A$ 1990;264:1284-6. 